\title{
Proposed salvage treatment strategy for biochemical failure after radical prostatectomy in patients with prostate cancer: a retrospective study
}

Makito Miyake ${ }^{1}$, Nobumichi Tanaka ${ }^{\text {* }}$ Isao Asakawa², Yosuke Morizawa', Satoshi Anai ${ }^{1}$, Kazumasa Torimoto', Katsuya Aoki ${ }^{1}$, Tatsuo Yoneda ${ }^{1}$, Masatoshi Hasegawa ${ }^{2}$, Noboru Konishi ${ }^{3}$ and Kiyohide Fujimoto ${ }^{1}$

\begin{abstract}
Background: Treatment options for patients with recurrent disease after radical prostatectomy include salvage radiotherapy of the prostatic bed and/or androgen deprivation therapy. To establish an effective treatment strategy for recurrent disease after radical prostatectomy, we retrospectively analyzed the outcome of salvage radiation monotherapy in such cases.

Methods: Data from 61 men who had undergone salvage radiation monotherapy for biochemical recurrent disease after radical prostatectomy were retrospectively reviewed. In all patients, salvage radiotherapy consisted of iraradiation to the prostatic bed (70 Gy) using three-dimensional conformal radiotherapy techniques. Treatment outcome was analyzed to identify predictive factors of salvage radiotherapy.

Results: The biochemical recurrence-free survival after salvage radiation monotherapy at 2 and 5 years was 55\% and $38 \%$, respectively. Cox proportional regression models revealed that the independent predictive factors for biochemical recurrence were Gleason Score $\geq 8$, negative surgical margin, and PSA velocity $\geq 0.38 \mathrm{ng} / \mathrm{mL} /$ year. Negative surgical margin and PSA velocity $\geq 0.8 \mathrm{ng} / \mathrm{mL} /$ year were significantly associated with poor response in the serum PSA levels after salvage radiotherapy.
\end{abstract}

Conclusions: Based on our findings, we propose a treatment strategy for biochemical recurrent disease after radical prostatectomy. Patients with Gleason score $\leq 7$, positive surgical margin, and PSA velocity $<0.38 \mathrm{ng} / \mathrm{mL} /$ year are categorized the most favorable group, so that eradication by salvage radiation monotherapy could be expected. Other patients could be divided to two groups depending on surgical margin status and PSA velocity: 1) patients who might require combination of SRT and short-term androgen deprivation therapy and 2) patients who should be treated by androgen deprivation monotherapy.

Keywords: Prostate cancer, Biochemical failure, Salvage radiotherapy, Prostate-specific antigen, PSA doubling time, PSA velocity

\footnotetext{
*Correspondence: sendo@naramed-u.ac.jp

'Department of Urology, Nara Medical University, 840 Shijo-cho, Nara 634-8522, Japan

Full list of author information is available at the end of the article
} 


\section{Introduction}

Radical prostatectomy is selected as the initial therapy in $44 \%$ of American men with prostate cancer (PCa) [1]. Our data from Nara Uro-Oncological Research Group (NUORG) in Japan show an RP rate of approximately 30\% ( $40 \%$ in stage cT1-2N0M0) with rates of radiation therapy, [2] but the proportion of radiation therapy is increasing $[3,4]$. In case of stage cT1-2N0M0 PCa, the corresponding figure was $40 \%$ es. Although RP provides excellent cancer control, $15 \%$ to $40 \%$ of these men will experience recurrent disease within 5 years presenting as an increasing serum prostate-specific antigen (PSA) level without radiographic evidence of cancer [5-8]. Extraprostatic extension, seminal vesicle invasion and positive surgical margins are widely recognized risk factors of recurrence after RP. Three large randomized trials evaluating the role of post-RP adjuvant radiotherapy for $\mathrm{PCa}$ with these risk factors have been completed so far [9-11]. Adjuvant radiotherapy for patients with high-risk PCa provides significant improvement of biochemical recurrence (BCR)-free survival and clinical recurrence-free survival. These results have raised debate as to whether all patients with the risk factors should receive immediate adjuvant radiotherapy, or whether close surveillance and salvage radiotherapy (SRT) performed as soon as BCR is detected can provide a similar benefit and avoid overtreatment of men in whom disease does not progress. SRT is the only salvage therapy that can potentially achieve long-term freedom from BCR and clinical progression [12-15].

A critical issue in the management of these patients is to determine whether a rising serum PSA level after RP represents isolated recurrence of the surgical prostate bed or occult remote metastases that are undetectable by imaging. The former can potentially be eradicated by SRT. For the best chance of success, SRT of the surgical site must be administered when the recurrent tumor is localized and the tumor burden is low. Androgendeprivation therapy (ADT) seems to provide only palliation to patients with recurrent prostate cancer.

To evaluate the benefit of SRT, we retrospectively reviewed a patient cohort of men who had undergone SRT monotherapy for the treatment of BCR after RP. We assessed their BCR-free survival to identify which subgroup had the greatest benefit from SRT, which subgroup needed combination therapy with SRT and ADT, and which subgroup received no benefit from SRT. To our knowledge, this is the first study in which three different groups were set based on the outcome of SRT to assess the clinicopathological background and detect predictive factors for the outcome of SRT.

\section{Materials and methods Patients}

There were 94 consecutive patients who underwent SRT for the treatment of BCR after RP from January 2008 to
December 2012 at Nara Medical University Hospital. Among them, 33 patients (35.1\%) received ADT before the completion of SRT, including neoadjuvant therapy prior to RP and adjuvant therapy after RP and were excluded from analysis. Patient allocation was not randomized, but depended on the clinician's decision. Thus for this study, we retrospectively reviewed the medical records of 61 patients who did not undergo ADT before the completion of SRT monotherapy. Medical records were reviewed for relevant clinicopathological information. Gleason score on prostate biopsy and radical prostatectomy specimen reported tumor grade. The 2002 TNM classification was used for staging [16]. Furthermore, patients were characterized into prognostic risk groups based on the NCCN classification system [17]. In all patients, digital rectal examination, pulmonary and abdominal computed tomography, and bone scans were performed before the initiation of SRT. No patients had any findings suggesting of distant metastases.

PSA doubling time (PSADT) and PSA velocity (PSAV) between the post-prostatectomy PSA nadir and the initiation of SRT was calculated using at least two PSA measurements with a 3-month interval and $\log$ calculations on the website of the Memorial Sloan Kettering Cancer Center (http://nomograms.mskcc.org/ Prostate/PsaDoublingTime.aspx).

The protocol for the research project was approved by the Institutional Review Board for Clinical Studies (Medical Ethics Committee) and the study was conducted in compliance with the protocol and in accordance with the provisions of the Declaration of Helsinki (2010).

\section{Salvage radiotherapy (SRT)}

SRT was defined as local radiotherapy to the prostatic bed alone following BCR after RP. All patients managed were seen at Nara Medical University Hospital and underwent simulation prior to treatment with three-dimensional conformal radiotherapy (3D-CRT) techniques with the treatment fields encompassing the prostatic and seminal vesicle bed plus periprostatic tissues. No attempt was made to comprehensively irradiate pelvic lymph nodes. Per our protocol, 70 Gy was delivered in daily fractions of $2.0 \mathrm{~Gy}$. The fields were shaped to protect the small bowels, bladder, and posterior rectal wall.

\section{Post-SRT evaluation}

After SRT was completed, patients were evaluated by measuring PSA every 3 to 4 months for 5 years, and every 6 to 12 months thereafter. Median follow-up period was 29.6 months (12.0 - 70.0). The primary endpoint of this study was BCR after SRT. We divided the 61 patients into three groups according to the BCR status and the progress of treatment (Figure 1). The first group was defined as the SRT success group, and consisted of patients 


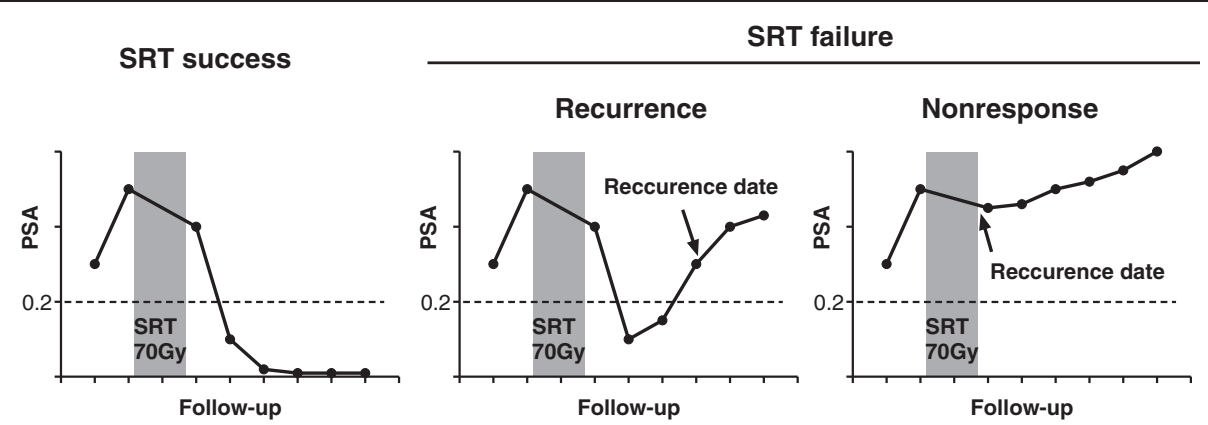

Figure 1 Changes in serum PSA levels of patients who underwent salvage radiotherapy (SRT) for recurrent disease after radical prostatectomy. Patients were evaluated by PSA measurement at regular intervals after completing SRT. Patients who showed a decline to PSA $<0.2 \mathrm{ng} / \mathrm{mL}$ after SRT and maintained PSA $<0.2 \mathrm{ng} / \mathrm{mL}$ during the follow-up were categorized as the SRT success group (left). Patients who showed a decline to PSA $<0.2 \mathrm{ng} / \mathrm{mL}$ after SRT and thereafter experienced a rise in PSA at two consecutive measurement points with the last PSA $\geq 0.2 \mathrm{ng} / \mathrm{mL}$ (middle) were categorized as the recurrence group. If the PSA continued to rise without a decline to PSA $<0.2 \mathrm{ng} / \mathrm{mL}$ after SRT, patients were categorized as the nonresponse group (right). The recurrence group and the nonresponse group were defined as the SRT failure group.

who showed a decline to PSA $<0.2 \mathrm{ng} / \mathrm{mL}$ after SRT and maintained PSA $<0.2 \mathrm{ng} / \mathrm{mL}$ during the follow-up (Figure 1, left). The second group was defined as the recurrence group, and consisted of patients who showed a decline to PSA $<0.2 \mathrm{ng} / \mathrm{mL}$ after SRT, and then experienced a rise in PSA at two consecutive measurement points to PSA $\geq$ $0.2 \mathrm{ng} / \mathrm{mL}$ at the last two measurement points (Figure 1, middle). The BCR date was defined as the first date with $\mathrm{PSA} \geq 0.2 \mathrm{ng} / \mathrm{mL}$ in the recurrence group. The third group was defined as the nonresponse group. If the PSA continued to rise without a decline to PSA $<0.2 \mathrm{ng} / \mathrm{mL}$ after SRT, it was considered as nonresponse to SRT (Figure 1, right). The BCR date was the date of the completion of SRT in the nonresponse group. The recurrence group and the nonresponse group were categorized as the SRT failure group (Figure 1, middle and right). All endpoints were calculated from the date of the completion of SRT.

\section{Statistical analysis}

Student's t-test, Mann Whitney U-test, the chi-square test, and Fisher's exact test were used to analyze the clinicopathological variables. The correlation between PSAV and PSADT was performed with Spearman's correlation analysis. BCR-free survival curves were plotted according to the Kaplan Meier method, and the log-rank test was applied for statistical significance. We used multivariate Cox proportional hazards regression models of several clinicopathological variables to identify independent predictors of a poor response to SRT. The association was evaluated using the odds ratio (OR) and 95\% confidence interval (CI) derived by standard logistic regression methods. For multivariate analysis, variables were selected on the condition that the $\mathrm{P}$ value was less than 0.1 in the univariate analysis. $\mathrm{P}$ values less than 0.05 were considered statistically significant. Statistical analysis was performed with SPSS Statistical Package version 20.0 (SPSS Inc., Chicago, IL).

\section{Results}

A total of $31(50.8 \%)$ out of 61 patients showed BCR after SRT. The SRT failure group consisted of 16 patients in the recurrence group and 15 patients in the nonresponse group. The BCR free-survival at 2 and 5 years, respectively, was $55 \%$ and $38 \%$ (Figure 2A). No patients died of prostate cancer, but one patient died of lung cancer during the follow-up. Grade 3 and 4 adverse events after SRT were not observed. All patient characteristics are listed and the statistical comparison of the SRT success and SRT failure groups is shown in Table 1. There were no differences between the SRT success group and the SRT failure group according to age, initial PSA, risk classification, prostatectomy Gleason score (GS), pathological $\mathrm{T}$ stage, lymphatic invasion (ly), perineural invasion (pn), or surgical margin status using contingency table analysis (Table 1). However, univariate survival analysis demonstrated that BCR after SRT had a significant association with higher GS (Figure $2 \mathrm{~B}, \mathrm{P}=0.047$ ), while positive surgical margin approached significance (Figure $2 \mathrm{C}$, $\mathrm{P}=0.075)$. Among the PSA-related continuous values, pre-SRT PSA and PSAV were significantly higher and PSADT was significantly shorter in the SRT failure groups compared to the SRT success groups. The optimal cutoff of pre-SRT PSA, PSAV, and PSADT, respectively, was set as $0.37 \mathrm{ng} / \mathrm{mL}, 0.38 \mathrm{ng} / \mathrm{mL} /$ year, and 6.0 months, by testing all the data points yielding the highest p-value in each intergroup comparison (Figure 2D-F). All three values could be strong predictive parameters of $\mathrm{BCR}$ after SRT over time. Since Spearman's correlation analysis showed that there was a high correlation between PSAV and PSADT $(\mathrm{P}<0.0001 ; \mathrm{r}=-0.74,95 \%$ confidence interval -0.84 to -0.60 ) and PSAV was a better predictor than PSADT (Figure 2E and F), PSAV was selected for multivariate survival analysis. Multivariate Cox proportional hazard analysis revealed that BCR was significantly associated with GS $\geq 8$ (HR 2.57, 95\% CI 1.12-5.89), a 


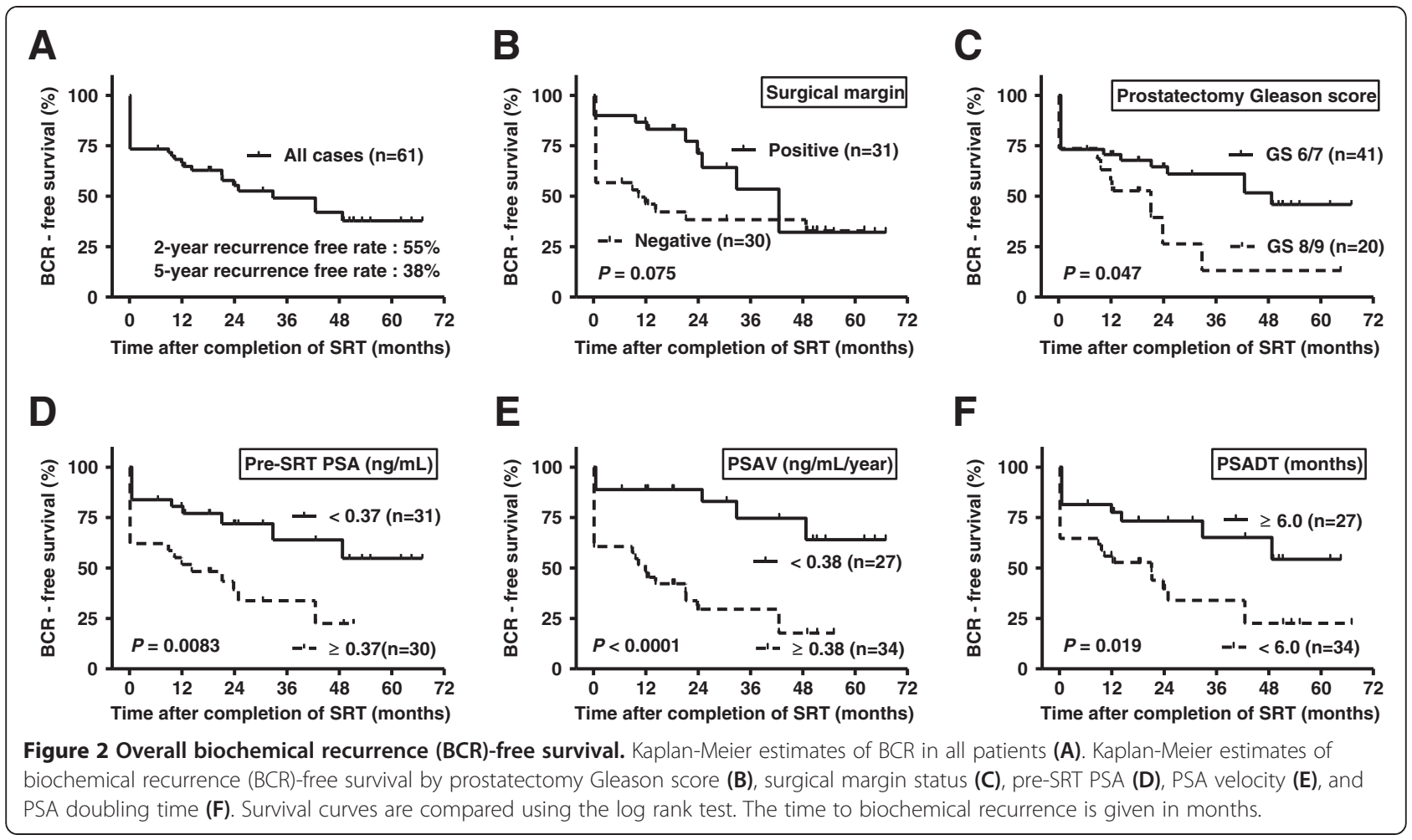

negative surgical margin (HR 2.39, 95\% CI 1.02-5.59), and PSAV $\geq 0.38 \mathrm{ng} / \mathrm{mL} /$ year (HR 4.44, 95\% CI 1.58-12.5) (Table 2). In the most favorable subgroup of patients with GS $\leq 7$, positive surgical margin, and PSAV $<0.38 \mathrm{ng} / \mathrm{mL} /$ year, only one of 10 cases (10\%) experienced BCR after SRT, while in the least favorable group of patients GS $>8$, negative surgical margin and PSAV $>0.38 \mathrm{ng} / \mathrm{mL} /$ year, all the four cases experienced BCR after SRT.

Next, we set out to determine which clinicopathological parameters which could distinguish between the recurrence group and the nonresponse group within the SRT failure group. Three PSA-related values associated with BCR after SRT were compared between the recurrence group and the nonresponse group (Figure 3). While the PSADT did not show any differences, there was a significant difference in PSAV $(P=0.044)$ and a marginal difference in pre-SRT PSA $(P=0.07)$. In a total of 31 cases consisting of 16 cases in the recurrence group and 15 cases in the nonresponse group, we determined optimal cut-off values of pre-SRT PSA and PSAV using a dichotomous test. Pre-SRT PSA $\geq 0.5 \mathrm{ng} / \mathrm{mL}$ and PSAV $\geq 0.8 \mathrm{ng} / \mathrm{mL} /$ year were significant parameters distinguishing the nonresponse group from the recurrence group (Table 3). Univariate analysis revealed that only negative surgical margin (odds ratio $=5.14 ; \mathrm{P}=0.038$ ) was associated with nonresponse to SRT. Multivariate logistic regression analysis also identified negative surgical margin (odds ratio $=12.71$; $\mathrm{P}=0.039$ ) and PSAV $\geq 0.8 \mathrm{ng} / \mathrm{mL} /$ year (odds ratio $=12.14$;
$\mathrm{P}=0.039$ ) as independent predictors of a poor response to SRT.

\section{Discussion}

Approximately one third of men undergoing RP for curative intent of their PCa will experience BCR within 5 years following RP [5-9]. If salvage therapy is withheld, two-thirds of recurrent cases will develop bone metastases within 10 years of BCR [18]. Salvage therapies with the intent to cure after BCR PCa consist of SRT and SRT with concomitant ADT. ADT along with SRT or as monotherapy should only be selected in cases that cannot be cured with SRT monotherapy, because ADT can have deleterious effects on the quality of life, increased risks for serious health concerns, and psychological distress $[19,20]$. However, there are uncertainties about the optimal timing of SRT after RP (adjuvant setting or salvage setting), especially in ethnic groups that were not represented well in the three randomized trials on post-operative radiation after RP [9-11].

In this study, we retrospectively reviewed a patient cohort of men who had undergone SRT monotherapy to identify prognostic factors for BCR after SRT. Our findings demonstrated that GS 8 or more, negative surgical margin, and PSAV $\geq 0.38 \mathrm{ng} / \mathrm{mL} /$ year were independent predictive factors for poor SRT sensitivity (Table 3). Only one of 10 cases (10\%) with three favorable factors (GS $\leq 7$, positive surgical margin, and PSAV $<0.38 \mathrm{ng} / \mathrm{mL} /$ year) 
Table 1 Characteristics of 61 patients undergoing SRT and comparison of SRT success group and SRT failure group

\begin{tabular}{|c|c|c|c|c|}
\hline Variables & Total $(n=61)$ & $\begin{array}{l}\text { SRT success } \\
(\mathrm{n}=30)\end{array}$ & $\begin{array}{l}\text { SRT failure } \\
(\mathrm{n}=31)\end{array}$ & $\begin{array}{l}\text { SRT Success vs SRT } \\
\text { failure } P \text { value }\end{array}$ \\
\hline Age at SRT (median, range) & $69(57-78)$ & $70(58-77)$ & $69(57-78)$ & $0.88+$ \\
\hline Initial PSA (mean, SD) & $12.5 \pm 14.5$ & $14.3 \pm 19.7$ & $10.7 \pm 6.4$ & $0.96+$ \\
\hline Clinical T stage & & & & $0.47 \neq$ \\
\hline T1c & 24 & 13 & 11 & \\
\hline T2 & 29 & 12 & 17 & \\
\hline T3 & 8 & 5 & 3 & \\
\hline NCCN risk classification & & & & $0.086 \neq$ \\
\hline Low & 10 & 8 & 2 & \\
\hline Intermidiate & 28 & 11 & 17 & \\
\hline High / Very high & 23 & 11 & 12 & \\
\hline Prostatectomy Gleason score & & & & $0.17 \neq$ \\
\hline 6 & 6 & 5 & 1 & \\
\hline 7 & 35 & 18 & 17 & \\
\hline 8 & 8 & 2 & 6 & \\
\hline 9 & 12 & 5 & 7 & \\
\hline Prostatectomy pathological T stage & & & & $0.84 \ddagger$ \\
\hline $\mathrm{T} 2 \mathrm{a}$ & 10 & 6 & 4 & \\
\hline $\mathrm{T} 2 \mathrm{~b}$ & 10 & 4 & 6 & \\
\hline $\mathrm{T} 2 \mathrm{c}$ & 14 & 7 & 7 & \\
\hline $\mathrm{T} 3 \mathrm{a} / \mathrm{b}$ & 27 & 13 & 14 & \\
\hline Prostatectomy lymphatic invasion (ly) & & & & $0.23 \neq$ \\
\hline Negative & 46 & 25 & 21 & \\
\hline Positive & 15 & 5 & 10 & \\
\hline Prostatectomy perineural invasion (pn) & & & & $0.79 \neq$ \\
\hline Negative & 23 & 12 & 11 & \\
\hline Positive & 38 & 18 & 20 & \\
\hline Prostatectomy Seminal vesicle involvement & & & & $0.97 \ddagger$ \\
\hline Negative & 57 & 28 & 29 & \\
\hline Positive & 4 & 2 & 2 & \\
\hline Surgical margins & & & & $0.075 \neq$ \\
\hline Negative & 30 & 11 & 19 & \\
\hline Positive & 31 & 19 & 12 & \\
\hline Time to PSA nadir after prostatectomy (months) & $2.4(0.8-17.9)$ & $2.3(0.8-15.8)$ & $2.5(0.9-17.9)$ & $0.22 \dagger$ \\
\hline PSA nadir after prostatectomy $(\mathrm{ng} / \mathrm{mL})$ & $0.140 \pm 0.238$ & $0.116 \pm 0.214$ & $0.163 \pm 0.262$ & $0.35+$ \\
\hline Pre-SRT PSA $(\mathrm{ng} / \mathrm{mL})$ & $0.56 \pm 0.49$ & $0.37 \pm 0.25$ & $0.75 \pm 0.59$ & $0.021+$ \\
\hline PSAV after PSA recurrence (ng/mL/year) & $0.19 \pm 1.40$ & $0.38 \pm 0.40$ & $1.43 \pm 1.79$ & $<0.0001+$ \\
\hline PSADT after PSA recurrence (months) & $7.44 \pm 7.27$ & $9.89 \pm 9.02$ & $5.07 \pm 3.94$ & $0.0049+$ \\
\hline Follow up period after SRT (months) & $29.6(12.0-70.0)$ & $24.6(12.0-70.0)$ & $31.2(12.0-64.6)$ & $0.83+$ \\
\hline
\end{tabular}

SRT = salvage radiotherapy; PSA = prostate-specific antigen; SD = standard deviation; NCCN = The National Comprehensive Cancer Network; PSAV = PSA velocity; PSADT = PSA doubling time; † Man-Whitney $U$ test; $\neq$ Chi-square test or Fisher's exact test.

experienced BCR after SRT, while all of four cases with the three adverse factors (GS $\leq 8$, negative surgical margin and PSAV $\geq 0.38$ experienced BCR after SRT. A consensus report from the Genito-Urinary Radiation
Oncologists of Canada (GUROC) show that a number of factors could predict disease progression: high GS, short PSADT, high pre-SRT PSA, negative surgical margin, and seminal vesicle involvement at the time of RP [15]. 
Table 2 Cox proportional models for SRT failure risks

\begin{tabular}{lccc}
\hline Variables & HR & $95 \% \mathrm{Cl}$ & $P$ value \\
\hline $\begin{array}{l}\text { Prostatectomy Gleason score } \\
\quad 6 / 7\end{array}$ & 1 & & \\
$\quad 8$ / 9 & 2.57 & $1.12-5.89$ & 0.026 \\
Surgical margin & & & \\
$\quad$ Positive & 1 & & \\
$\quad$ Negative & 2.39 & $1.02-5.59$ & 0.045 \\
Pre-SRT PSA (ng/mL) & & & \\
$\quad<0.37$ & 1 & & \\
$\quad \geq 0.37$ & 1.18 & $0.48-2.89$ & 0.71 \\
PSAV (ng/mL/year) & & & \\
$\quad<0.38$ & 1 & & 0.005 \\
$\quad \geq 0.38$ & 4.44 & $1.58-12.5$ & \\
\hline
\end{tabular}

$\mathrm{HR}=$ Hazard ratio; $\mathrm{Cl}=$ confidence interval; $\mathrm{SRT}=$ salvage radiotherapy; PSAV $=$ PSA velocity.

In most previously published studies, patients who were treated with ADT before the completion of SRT, such as a neoadjuvant agents or adjuvant agents in association with RP, were enrolled. Statistics can be biased by the inclusion of patients who had undergone ADT before the completion of SRT if disease progression is defined as a rise in PSA. In our study, we excluded 33 patients who were treated with ADT before the completion of SRT, yielding 61 patients who were treated with SRT monotherapy for recurrent disease after RP. The exclusion enabled a unique analysis and identification of clincopathological factors predicting SRT-success, recurrence, and nonresponse groups.

SRT monotherapy should be selected for patients with favorable factors while ADT alone could be selected for patients in whom eradication of the recurrent disease after RP is unlikely. Figure 4 shows a proposed treatment strategy based on our findings. In patients harboring three favorable factors including low GS, positive surgical margin, and low PSAV, eradication by SRT monotherapy can be expected. In contrast, in patients who do not meet the conditions of favorable factors, it can be suspected that radiation-resistant local recurrent tumor, remote micro-metastases, or both may develop. It means that in patients without the three favorable factors, SRT monotherapy will likely prove inadequate to eradicate recurrent disease. Thus these patients can be divided according to the treatment progress into two groups: those showing biochemical recurrence after a decline to $\mathrm{PSA}<0.2 \mathrm{ng} / \mathrm{mL}$, and those presenting with nonresponse to SRT. The former (positive surgical margins or PSAV <0.8) predominantly includes patients who are unable to be salvaged by SRT monotherapy and who require combination with short-term ADT. The latter (negative surgical margins and PSAV $\geq 0.8$ ) predominantly
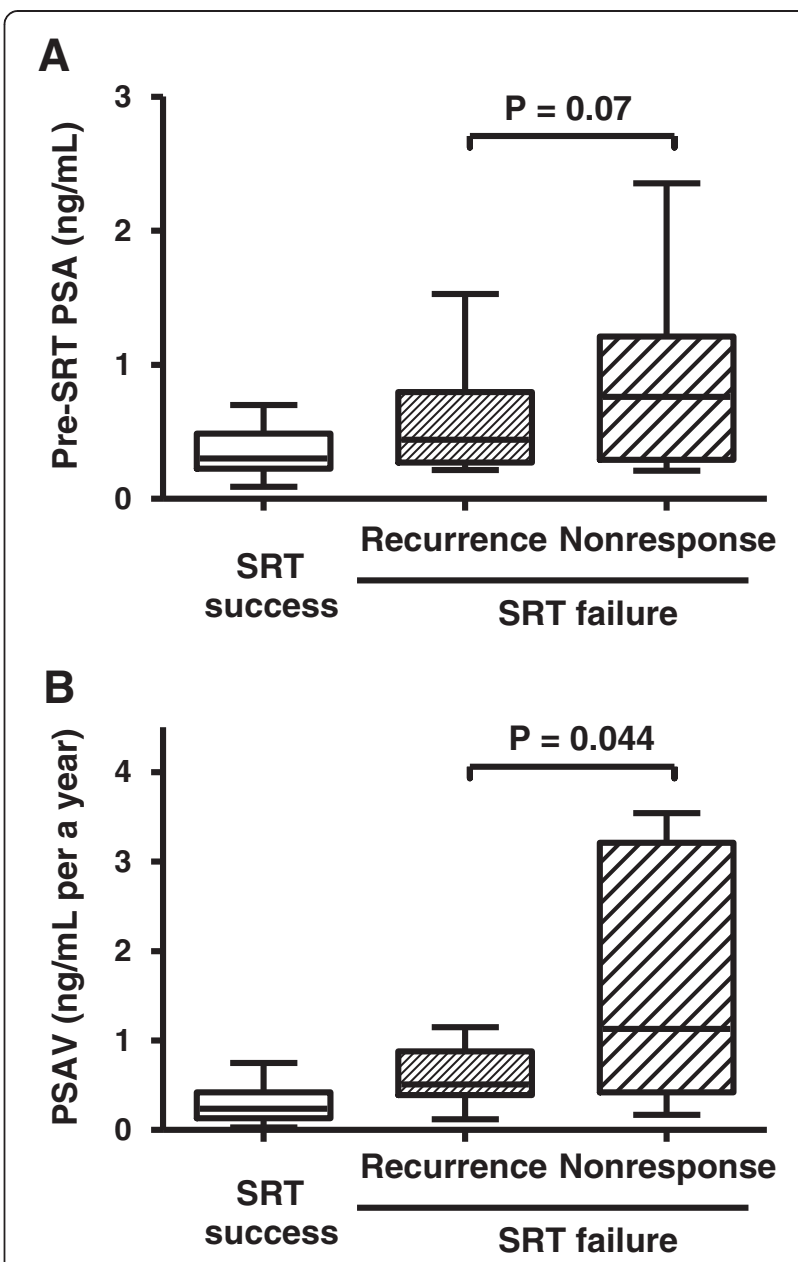

C

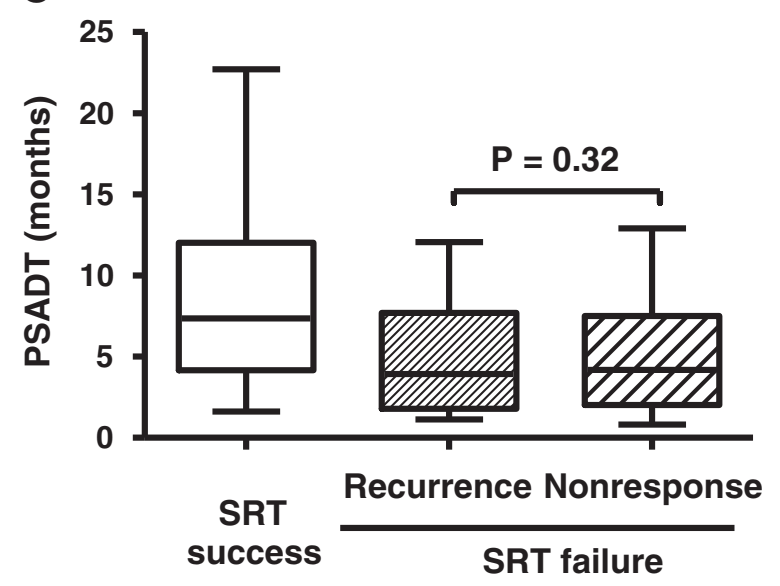

Figure 3 Comparison of PSA-related values between the SRT success group, recurrence group and nonresponse group. Pre-SRT PSA (A), PSAV (B), and PSADT (C) were depicted by Tukey box plots. Horizontal lines within boxes indicate median levels and are depicted by horizontal lines within boxes. Significance $(P<0.05)$ was assessed by the Mann-Whitney $U$ test. 
Table 3 Univariate and multivariate analysis of factors in the SRT failure group that distinguish the nonresponse group from the recurrence group

\begin{tabular}{|c|c|c|c|c|c|c|}
\hline \multirow{2}{*}{ Variables } & \multicolumn{3}{|c|}{ Univariate analysis } & \multicolumn{3}{|c|}{ Multivariate analysis $\dagger$} \\
\hline & OR & $95 \% \mathrm{Cl}$ & $P$ value & OR & $95 \% \mathrm{Cl}$ & $P$ value \\
\hline \multicolumn{7}{|c|}{ Prostatectomy Gleason score } \\
\hline $6 / 7$ & 1 & & & & & \\
\hline $8 / 9$ & 0.5 & $0.12-2.14$ & 0.35 & & & \\
\hline \multicolumn{7}{|c|}{ Prostatectomy lymphatic invasion (ly) } \\
\hline Negative & 1 & & & 1 & & \\
\hline Positive & 3.79 & $0.75-19.1$ & 0.097 & 2.95 & $0.30-29.4$ & 0.36 \\
\hline \multicolumn{7}{|c|}{ Prostatectomy perineural invasion (pn) } \\
\hline Negative & 1 & & & 1 & & \\
\hline Positive & 4.00 & $0.81-19.8$ & 0.081 & 3.56 & $0.47-26.8$ & 0.22 \\
\hline \multicolumn{7}{|c|}{ Surgical margin } \\
\hline Positive & 1 & & & 1 & & \\
\hline Negative & 5.14 & $1.03-25.6$ & 0.038 & 12.71 & $1.14-142.1$ & 0.039 \\
\hline \multicolumn{7}{|c|}{ Pre-SRT PSA (ng/mL) } \\
\hline$<0.5$ & 1 & & & & & \\
\hline$\geq 0.5$ & 3.33 & $0.76-14.6$ & 0.11 & & & \\
\hline \multicolumn{7}{|c|}{ PSAV (ng/mL/year) } \\
\hline$<0.8$ & 1 & & & 1 & & \\
\hline$\geq 0.8$ & 4.13 & $0.88-19.3$ & 0.065 & 12.14 & $1.13-129.9$ & 0.039 \\
\hline
\end{tabular}

$\mathrm{OR}=$ Odds ratio; $\mathrm{Cl}$ = confidence interval; $\mathrm{SRT}=$ salvage radiotherapy; PSAV = PSA velocity; † Logistic regression analysis.

includes patients who do not benefit from SRT and should be treated by ADT monotherapy.

There are several limitations of the current study including it being a retrospective study design with a small sample size from a single-center and there being selection bias. Furthermore, the study lacks overall survival and cause-specific survival analysis due to the short follow-up period. Validation of these results in future prospective multi-center studies will be needed.

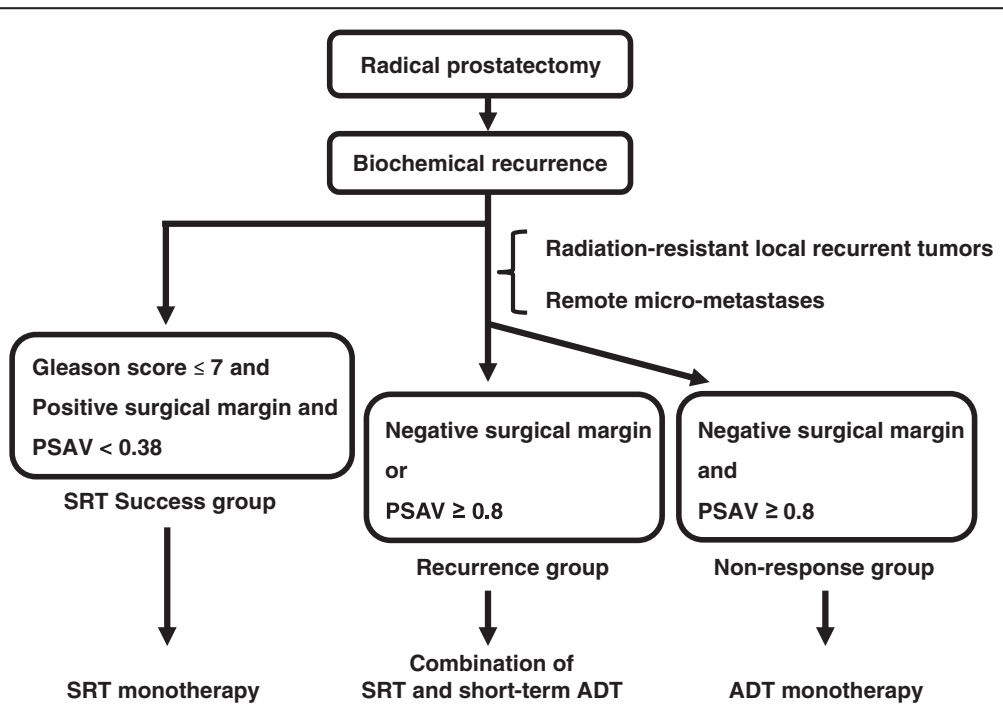

Figure 4 Proposed treatment strategy for recurrent disease after radical prostatectomy. The OR that patients with three favorable factors will experience BCR after SRT monotherapy is 0.084 (95\% Cl 0.01-0.72). Patients showing biochemical recurrence after a decline to PSA $<0.2 \mathrm{ng} /$ $\mathrm{mL}$ and those showing nonresponse to SRT can be distinguished by the status of the surgical margin and PSAV. The former may benefit from the combination of SRT and short course of ADT, while the latter may not receive benefit from SRT. 


\section{Consent}

Written informed consent was obtained from the patient for the publication of this report and any accompanying images.

\section{Abbreviations}

RP: Radical prostatectomy; SRT: Salvage radiotherapy; PSA: Prostate-specific antigen; PCa: Prostate cancer; BCR: Biochemical recurrence; ADT: Androgen-deprivation therapy; PSADT: PSA doubling time; PSAV: PSA velocity; GS: Gleason score.

\section{Competing interests}

The authors declare that they have no competing interests.

\section{Authors' contributions}

MM and NT contributed to the design of study and writing the manuscript. $\mathrm{IA}$ and $\mathrm{MH}$ performed treatment planning. $\mathrm{YM}$ and $\mathrm{SA}$ assisted with the acquisition of patients' data. KT, KA and TY helped with writing manuscript. NK reviewed pathologic diagnosis of prostatectomy tissues. KF was involved in the design of study and wrote the manuscript. All authors reviewed and approved the final manuscript.

\section{Author details}

'Department of Urology, Nara Medical University, 840 Shijo-cho, Nara 634-8522, Japan. ${ }^{2}$ Department of Radiation Oncology, Nara Medical University, 840 Shijo-cho, Nara 634-8522, Japan. ${ }^{3}$ Department of Pathology, Nara Medical University, 840 Shijo-cho, Nara 634-8522, Japan.

Received: 10 July 2014 Accepted: 16 August 2014

Published: 20 October 2014

\section{References}

1. Cooperberg MR, Lubeck DP, Penson DF, Mehta SS, Carroll PR, Kane CJ: Sociodemographic and clinical risk characteristics of patients with prostate cancer within the Veterans Affairs health care system: data from CaPSURE. J Urol 2003, 170:905-908.

2. Tanaka N, Fujimoto K, Hirayama A, Yoneda T, Yoshida K, Hirao Y: Trends of the primary therapy for patients with prostate cancer in Nara urooncological research group (NUORG): a comparison between the CaPSURE data and the NUORG data. Jpn J Clin Oncol 2010, 40:588-592.

3. Tanaka N, Hirayama A, Yoneda T, Yoshida K, Shimada K, Konishi N, Fujimoto K: Trends of risk classification and primary therapy for Japanese patients with prostate cancer in Nara Uro-Oncological Research Group (NUORG)-a comparison between 2004-2006 and 2007-2009. BMC Cancer 2013, 13:588.

4. Tanaka N, Fujimoto K, Hirayama A, Samma S, Momose H, Kaneko Y, Haramoto M, Hayashi Y, Nakagawa Y, Otani T, Watanabe S, Hirao Y: The primary therapy chosen for patients with localized prostate cancer between the university hospital and its affiliated hospitals in Nara Uro-Oncological Research Group registration. BMC Urol 2011, 11:6.

5. Tanaka N, Fujimoto K, Hirayama A, Samma S, Momose H, Kaneko Y, Haramoto M, Hayashi Y, Nakagawa Y, Otani T, Watanabe S, Hirao Y: Risk-stratified survival rates and predictors of biochemical recurrence after radical prostatectomy in a Nara, Japan, cohort study. Int J Clin Oncol 2011, 16:553-559.

6. Okajima E, Yoshikawa M, Masuda Y, Shimizu K, Tanaka N, Hirayama A, Shimada K, Fujimoto K, Hirao Y: Improvement of the surgical curability of locally confined prostate cancer including non-organ-confined high-risk disease through retropubic radical prostatectomy with intentional wide resection. World I Surg Oncol 2012, 10:249.

7. Tanaka N, Fujimoto K, Hirayama A, Nakai Y, Chihara Y, Anai S, Tomioka A, Shimada K, Konishi N, Hirao Y: Calculated tumor volume is an independent predictor of biochemical recurrence in patients who underwent retropubic radical prostatectomy. Adv Urol 2012, 2012:204215.

8. Han M, Partin AW, Pound CR, Epstein Jl, Walsh PC: Long-term biochemical disease-free and cancer-specific survival following anatomic radical retropubic prostatectomy: the 15-year Johns Hopkins experience. Urol Clin North Am 2001, 28:555-565.

9. Swanson GP, Hussey MA, Tangen CM, Chin J, Messing E, Canby-Hagino E, Forman JD, Thompson IM, Crawford ED: Predominant treatment failure in postprostatectomy patients is local: analysis of patterns of treatment failure in SWOG 8794. J Clin Oncol 2007, 25:2225-2229.

10. Van der Kwast TH, Bolla M, Van Poppel H, Van Poppel H, Van Cangh P, Vekemans K, Da Pozzo L, Bosset JF, Kurth KH, Schröder FH, Collette L: Identification of patients with prostate cancer who benefit from immediate postoperative radiotherapy: EORTC 22911. J Clin Oncol 2007, 25:4178-4186

11. Wiegel T, Bottke D, Steiner U, Siegmann A, Golz R, Störkel S, Willich N, Semjonow A, Souchon R, Stöckle M, Rübe C, Weissbach L, Althaus P, Rebmann U, Kälble T, Feldmann HJ, Wirth M, Hinke A, Hinkelbein W, Miller K: Phase III postoperative adjuvant radiotherapy after radical prostatectomy compared with radical prostatectomy alone in pT3 prostate cancer with postoperative undetectable prostate-specific antigen: ARO 96-02/AUO AP 09/95. J Clin Oncol 2009, 27:2924-2930.

12. Trock BJ, Han M, Freedland SJ, Humphreys EB, DeWeese TL, Partin AW, Walsh PC: Prostate cancer-specific survival following salvage radiotherapy vs observation in men with biochemical recurrence after radical prostatectomy. JAMA 2008, 299:2760-2769.

13. Katz MS, Zelefsky MJ, Venkatraman ES, Fuks Z, Hummer A, Leibel SA: Predictors of biochemical outcome with salvage conformal radiotherapy after radical prostatectomy for prostate cancer. J Clin Oncol 2003, 21:483-489.

14. Stephenson AJ, Scardino PT, Kattan MW, Pisansky TM, Slawin KM, Klein EA, Anscher MS, Michalski JM, Sandler HM, Lin DW, Forman JD, Zelefsky MJ, Kestin LL, Roehrborn CG, Catton CN, DeWeese TL, Liauw SL, Valicenti RK, Kuban DA, Pollack A: Predicting the outcome of salvage radiation therapy for recurrent prostate cancer after radical prostatectomy. J Clin Oncol 2007, 25:2035-2041.

15. Sia M, Pickles T, Morton G, Souhami L, Lukka H, Warde P: Salvage radiotherapy following biochemical relapse after radical prostatectomy: proceedings of the Genito-Urinary Radiation Oncologists of Canada consensus meeting. Urol Oncol 2008, 26:271-275.

16. Sobin LH, Wittekind CH (Eds): TNM Classification of Malignant Tumours. 6th edition. New York: Wiley-Liss; 2002.

17. Mohler J, Bahnson RR, Boston B, Kantoff P, Kozlowski JM, Kuettel M, Lange PH Logothetis C, Pow-Sang JM, Roach M 3rd, Sandler H, Scardino PT, Taylor RJ, Urban DA, Walsh PC, Wilson TG: NCCN clinical practice guidelines in oncology: prostate cancer. J Natl Compr Canc Netw 2000, 8:162-200.

18. Pound CR, Partin AW, Eisenberger MA, Chan DW, Pearson JD, Walsh PC: Natural history of progression after PSA elevation following radical prostatectomy. JAMA 1999, 281:1591-1597.

19. Higano CS: Side effects of androgen deprivation therapy: monitoring and minimizing toxicity. Urology 2003, 61:32-38.

20. Torimoto K, Samma S, Kagebayashi Y, Chihara Y, Tanaka N, Hirayama A Fujimoto K, Hirao Y: The effects of androgen deprivation therapy on lipid metabolism and body composition in Japanese patients with prostate cancer. Jpn J Clin Oncol 2011, 41:577-581.

\section{doi:10.1186/1748-717X-9-208}

Cite this article as: Miyake et al:: Proposed salvage treatment strategy for biochemical failure after radical prostatectomy in patients with prostate cancer: a retrospective study. Radiation Oncology 2014 9:208

\section{Submit your next manuscript to BioMed Central and take full advantage of:}

- Convenient online submission

- Thorough peer review

- No space constraints or color figure charges

- Immediate publication on acceptance

- Inclusion in PubMed, CAS, Scopus and Google Scholar

- Research which is freely available for redistribution 